\title{
HOI-02 induces apoptosis and G2-M arrest in esophageal cancer mediated by ROS
}

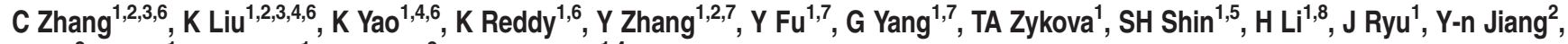 \\ $X$ Yin $^{2}$, W Ma ${ }^{1}$, AM Bode ${ }^{1}$, Z Dong ${ }^{\star, 2}$ and Z Dong ${ }^{\star, 1,4}$
}

Reactive oxygen species (ROS) are chemically reactive molecules that perform essential functions in living organisms. Accumulating evidence suggests that many types of cancer cells exhibit elevated levels of ROS. Conversely, generation of ROS has become an effective method to kill cancer cells. (E)-3-hydroxy-3-(4-(4-nitrophenyl)-2-oxobut-3-en-1-yl) indolin-2-one, which is an $\mathrm{NO}_{2}$ group-containing compound designated herein as $\mathrm{HOI}-02$, generated ROS and, in a dose-dependent manner, decreased esophageal cancer cell viability and inhibited anchorage-independent growth, followed by apoptosis and G2-M arrest. Moreover, results of an in vivo study using a patient-derived xenograft mouse model showed that $\mathrm{HOI}-02$ treatment suppressed the growth of esophageal tumors, without affecting the body weight of mice. The expression of Ki- 67 was significantly decreased with $\mathrm{HOI}-02$ treatment. In addition, the phosphorylation of c-Jun, and expression of p21, cleaved caspase 3, and DCFH-DA were increased in the HOI-02-treated group compared with the untreated control group. In contrast, treatment of cells with (E)-3-(4-(4-aminophenyl)-2oxobut-3-en-1-yl)-3-hydroxyindolin-2-one, which is an $\mathrm{NH}_{2}$ group-containing compound designated herein as $\mathrm{HOI}-11$, had no effect. Overall, we identified $\mathrm{HOI}-02$ as an effective $\mathrm{NO}_{2}$ group-containing compound that was an effective therapeutic or preventive agent against esophageal cancer cell growth.

Cell Death and Disease (2015) 6, e1912; doi:10.1038/cddis.2015.227; published online 15 October 2015

Esophageal cancer remains one of the most lethal cancers worldwide with its incidence on the rise. It is the fourth most frequently diagnosed cancer and the fourth leading cause of cancer death in China. ${ }^{1}$ In 2014 alone, esophageal cancer affected over 18000 people across the United States and approximately 15500 succumbed to this disease. ${ }^{2}$ Despite clinical advances in the field of oncology, esophageal cancer remains one of the leading causes of cancer-associated mortality. The overall 5 -year survival rate for all patients with esophageal cancer is $<20 \% .{ }^{3}$ Owing to its aggressive nature and poor response to chemotherapy, esophageal cancer remains a challenging disease to treat. ${ }^{2}$ Therefore, research to identify and develop more effective drugs to prevent or treat esophageal cancer is urgently needed.

Reactive oxygen species (ROS) production is a common characteristic of most non-surgical therapeutic approaches, including chemotherapy and radiotherapy, against various cancers because of the ability of ROS to trigger cancer cell death. ${ }^{4}$ More ROS-generating agents with different mechanisms of action are needed to fully understand their potential application in cancer treatment. ${ }^{5}$ Inducing ROS generation is considered a novel approach in cancer treatment ${ }^{6,7}$ and the advantage of this strategy lies in its selectivity. Cancer cells are usually under oxidative stress and, hence, already contain a relatively high basal level of ROS. ${ }^{8,9}$ A small induction of ROS in tumor cells may push the level of ROS over the threshold of life and death to induce cell death, whereas normal cells can better tolerate the oxidative insults because of their lower basal level of ROS and stronger antioxidant capacities. ${ }^{4}$ Hence, designing and producing drugs that can generate ROS to improve esophageal cancer treatment would be helpful and important.

In this study, we found that $\mathrm{HOI}-02$, which was synthesized in our laboratory, could dose dependently induce ROS production corresponding with decreased esophageal cancer cell viability and inhibition of anchorage-independent cell

\footnotetext{
${ }^{1}$ Department of Cellular and Molecular Biology, The Hormel Institute, University of Minnesota, Austin, MN, USA; ${ }^{2}$ Department of Pathology and Pathophysiology, Basic Medical College, Zhengzhou University, Zhengzhou, China; ${ }^{3}$ Department of Molecular Pathology, The Affiliated Cancer Hospital, Zhengzhou University, Zhengzhou, China; ${ }^{4}$ China-US (Henan) Hormel Cancer Institute, Zhengzhou, China and ${ }^{5}$ Program in Biomedical Informatics and Computational Biology, University of Minnesota, Minneapolis, MN, USA

${ }^{*}$ Corresponding author: Z Dong, Department of Pathology and Pathophysiology, Basic Medical College, Zhengzhou University, Zhengzhou, China. Tel: +86 371 67781956; Fax: +86 371 67781956; E-mail: dongzm @ zzu.edu.cn

or Z Dong, Department of Cellular and Molecular Biology, The Hormel Institute, University of Minnesota, Austin, MN 55912, USA. Tel: +1 507 437 9600; Fax: +1 507437 9606; E-mail: zgdong@hi.umn.edu

${ }^{6}$ These authors contributed equally to this work.

${ }^{7}$ Current address: The First Affiliated Hospital of Zhengzhou University, Zhengzhou, China

${ }^{8}$ Current address: School of Food Science and Technology, Jiangnan University, Wuxi, China

Abbreviations: AP-1, activator protein-1; ATM, ataxia telangiectasia mutated; BME, Basal medium Eagle; DAPI, 4,6-diamidino-2-phenylindole; DCFH-DA, 2,7dichlorodihydrofluorescein diacetate; DMPO, 5,5-dimethyl-1-pyrroline- $N$-oxide; DTPA, diethylenetriamine pentaacetate; EPR, electron paramagnetic resonance; FMN, riboflavin-5'-monophosphate; GSH, glutathione; $\mathrm{H}_{2} \mathrm{O}_{2}$, hydrogen peroxide; JNKs, c-Jun N-terminal kinases; NAC, $\mathrm{N}$-acetyl cysteine; NADPH, nicotinamide adenine dinucleotide phosphate; PARP, poly ADP-ribose polymerase; PBS, phosphate-buffered saline; PDX, patient-derived xenograft; ROS, reactive oxygen species; SDS, sodium dodecyl sulfate; SOD, superoxide dismutase; TUNEL, terminal deoxynucleotidyl transferase dUTP nick-end labeling

Received 16.2.2015; revised 28.5.2015; accepted 09.7.2015; Edited by G Dewson
} 
growth. Biologic testing further confirmed that $\mathrm{HOI}-02$ potently inhibited esophageal cancer cell growth by inducing apoptosis and G2-M arrest in vitro and in vivo. Signaling, involving c-Jun $\mathrm{N}$-terminal kinases (JNKs), AP-1, caspase 3, ATM, p53 and p21, was activated in cells treated with $\mathrm{HOI}-02$. Thus, $\mathrm{HOI}-02$ may be useful in prevention or treatment of esophageal cancer.

\section{Results}

HOI-02 decreases esophageal cancer cell viability and inhibits anchorage-independent cell growth. HOI-02 (Figure 1a, left panel, Supplementary Figure S1A) is a novel compound synthesized in our laboratory. Our data indicated that the viability KYSE30 (Figure 1a, middle panel) and KYSE510 (Figure 1a, right panel) esophageal cancer cells was decreased by $\mathrm{HOI}-02$ in a dose-dependent manner. Furthermore, we examined the effect of $\mathrm{HOl}-02$ on anchorage-independent growth of three esophageal cancer cell lines. We found that $\mathrm{HOI}-02$ inhibited anchorageindependent growth, leading to a dose-dependent reduction of colony formation (Figure 1b, Supplementary Figure S1B). At the same time, we examined the effect of another compound, $\mathrm{HOl}-11$ (Figure 1c, left panel, Supplementary Figure $\mathrm{S} 2 \mathrm{~A}$ ), which contains an $\mathrm{NH}_{2}$ group instead of the $\mathrm{NO}_{2}$ group. In contrast to $\mathrm{HOI}-02, \mathrm{HOl}-11$ had little or no effect on viability (Figure 1c, middle and right panels) or anchorageindependent growth (Figure 1d, Supplementary Figure S2B) of esophageal cancer cells. Only the highest concentration $(20 \mu \mathrm{M})$ could inhibit colony formation (Figure 1d).

\section{HOl-02 induces apoptosis and G2-M arrest in esophageal} cancer cells. To study the mechanism of the inhibitory effects of $\mathrm{HOI}-02$, apoptosis and cell cycle distribution were measured by flow cytometry using annexin V/propidium iodide (PI) staining. Treatment of KYSE510 cells with HOI-02 $(0,5,10$ or $20 \mu \mathrm{M})$ for $24 \mathrm{~h}$ resulted in increased numbers of apoptotic cells ranging from 9.54 to $57.58 \%$ (Figure 2a, upper panels) and amplification of G2-M phase arrest from 15.76 to $56.19 \%$ (Figure $2 \mathrm{a}$, lower panels). These results confirm that $\mathrm{HOI}-02$ induces apoptosis and G2-M phase arrest in esophageal cancer cells and thus inhibits their growth. We also treated cells with $\mathrm{HOl}-11$ under the same conditions as $\mathrm{HOI}-02$ and found that $\mathrm{HOl}-11$ could not induce apoptosis or G2-M arrest (Figure 2b). Furthermore, we quantified the level of apoptosis using the TUNEL assay (terminal deoxynucleotidyl transferase dUTP nick-end labeling) and found that TUNEL-positive cancer cells were significantly increased dose dependently with $\mathrm{HOI}-02$ treatment compared with the untreated control group (Figure 2c). This result confirms that $\mathrm{HOI}-02$ induces apoptosis of esophageal cancer cells.

ROS are involved in HOl-02-induced apoptosis and G2-M arrest in esophageal cancer cells. Treatment of KYSE510 cells with $20 \mu \mathrm{M} \mathrm{HOl-02} \mathrm{increased} \mathrm{the} \mathrm{generation} \mathrm{of} \mathrm{ROS} \mathrm{as}$ early as $1 \mathrm{~h}(44.72 \%)$ and the level of ROS peaked at $6 \mathrm{~h}$ (88.05\%; Figure 3a, upper panels). In contrast, treatment with $20 \mu \mathrm{M} \mathrm{HOl}-11$ had a smaller effect $(7.54 \%$ at $1 \mathrm{~h}$ and $26.32 \%$ at $6 \mathrm{~h}$, Figure $3 \mathrm{a}$, lower panels). Notably, treatment of KYSE510 cells with free radical scavengers, NAC, glutathione (GSH) or catalase, prevented the decrease in viability (Figure 3b), apoptosis (Figure 3c, upper panels) and G2-M arrest (Figure 3c, lower panels) induced by HOI-02. These results suggest that ROS have a role in the action of $\mathrm{HOI}-02$ against esophageal cancer cell growth.

EPR analysis confirms the involvement of ROS in the anticancer activity of $\mathrm{HOI}-02$. To further confirm that $\mathrm{ROS}$ are involved in HOI-02-induced apoptosis and G2-M arrest in esophageal cancer cells, the electron paramagnetic resonance (EPR) spin trapping regent, 5,5-dimethyl-1-pyrroline- $\mathrm{N}$-oxide (DMPO), was used to detect ROS generation in the presence of $\mathrm{HOI}-02$. In this experimental system, DMPO was added following the addition of nicotinamide adenine dinucleotide phosphate (NADPH) to phosphate-buffered saline (PBS) containing $\mathrm{FMN}$ and $\mathrm{HOI}-02$. The reaction was incubated in an anaerobic environment for $15 \mathrm{~min}$ to determine whether these aromatic nitro-containing compounds would generate their corresponding nitro anion free radical. ${ }^{10}$ The reaction containing riboflavin-5'-monophosphate (FMN), NADPH, DMPO and HOl-02 generated a strong radical signal in this system (Figure 4a). In contrast, when $\mathrm{HOl}-02$ was removed, a free radical signal was not detectable (Figure 4b). GSH or catalase, but not superoxide dismutase (SOD), could significantly decrease the signal, suggesting that that $\mathrm{H}_{2} \mathrm{O}_{2}$ or glutathione, but not $\mathrm{O}_{2}-$, may have a critical role in the effects of $\mathrm{HOl}-02$ treatment (Figures $4 \mathrm{c}-\mathrm{e}$ ). The generation of other free radicals such as $\mathrm{NO}$ and $\mathrm{NO}_{2}$ was not detected with EPR and iNOS was also not induced with $\mathrm{HOI}-02$ treatment as indicated by western blot analysis (Supplementary Figure S3). In addition, no radical signal was detected when $\mathrm{HOI}-02$ was replaced with $\mathrm{HOl}-11$ (Figure 4f). These studies indicate that ROS have a substantial role in $\mathrm{HOI}-02$ treatment.

HOI-02-induced apoptosis is mediated through the induction of AP-1 activity and the modulation of caspase activity. To delineate the mechanism of HOI-02-induced apoptosis, the expression of apoptosis-associated proteins was evaluated in KYSE510 cells after exposure to $20 \mu \mathrm{M}$ HOl-02 for various times $(0,1,3,6,12$ or $24 \mathrm{~h})$. Results indicate that $\mathrm{HOI}-02$ treatment increased the expression of cleaved caspase 3 , cleaved poly ADP-ribose polymerase (PARP) and Bax. These changes were accompanied by an increased expression of phosphorylation of c-Jun (Ser63), c-Fos (Ser32), JNKs (Thr183/Tyr185) and p38 (Thr180/ Tyr182) (Figure 5a). Moreover, we also observed that phosphorylation of c-Jun (Ser63) and c-Fos (Ser32) disappeared when treated with $\mathrm{HOl}-02$ and $\mathrm{NAC}$ or $\mathrm{GSH}$ simultaneously (Figure 5b). Furthermore, in cells treated with $\mathrm{H}_{2} \mathrm{O}_{2}(500 \mu \mathrm{M})$, phosphorylation of c-Jun (Ser63), c-Fos (Ser32), JNKs (Thr183/Tyr185) and p38 (Thr180/Tyr182) was also increased over time (Figure $5 \mathrm{c}$ ). c-Jun and c-Fos commonly interact to form the heterodimeric transcription factor, activator protein-1 (AP-1) and ROS have been reported to mediate AP-1 activity. ${ }^{11}$ Herein, we showed that HOl-02 could significantly induce AP-1 luciferase activity dose dependently and NAC or GSH could block the effect 
(Figure 5d). These results further suggest that HOI-02 exerts its effects by generating ROS, which then contribute to the activation of key apoptosis-related proteins.
HOI-02-induced G2-M arrest is mediated through p21-related signaling. We then examined the effect of $20 \mu \mathrm{M} \mathrm{HOl}-02$ at various time points on the expression of a<smiles>O=C(/C=C/c1ccc([N+](=O)[O-])cc1)CC1(O)C(=O)Nc2ccccc21</smiles>

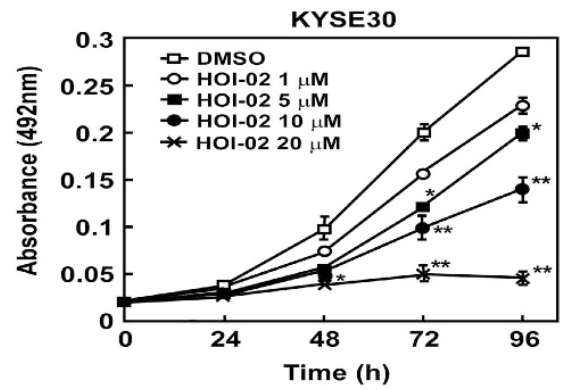

b

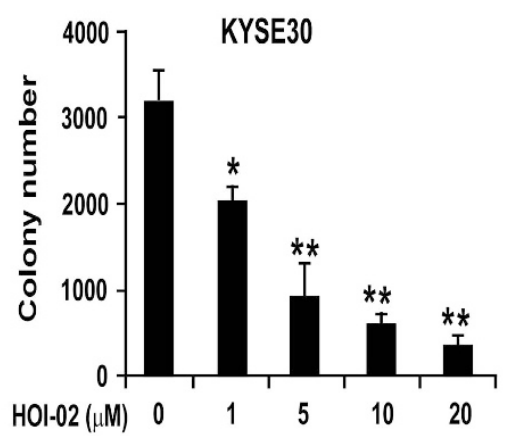

C<smiles>Nc1ccc(/C=C/C(=O)CC2(O)C(=O)Nc3ccccc32)cc1</smiles>

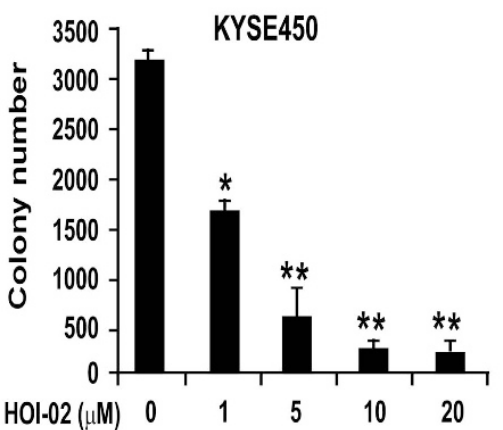

KYSE30

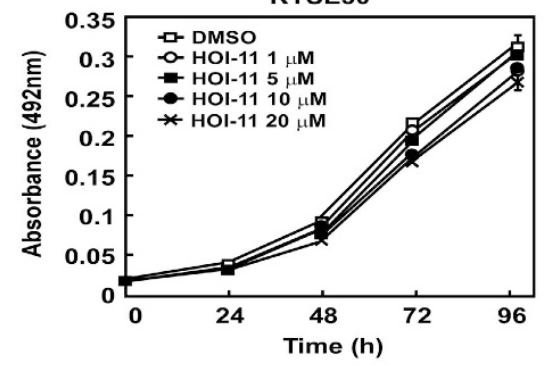

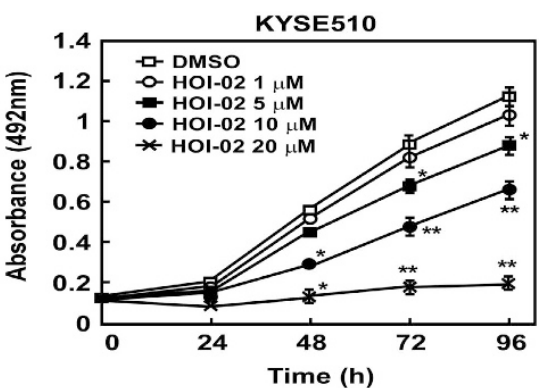

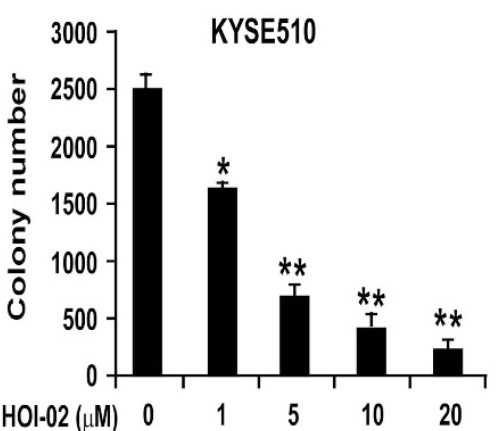

d

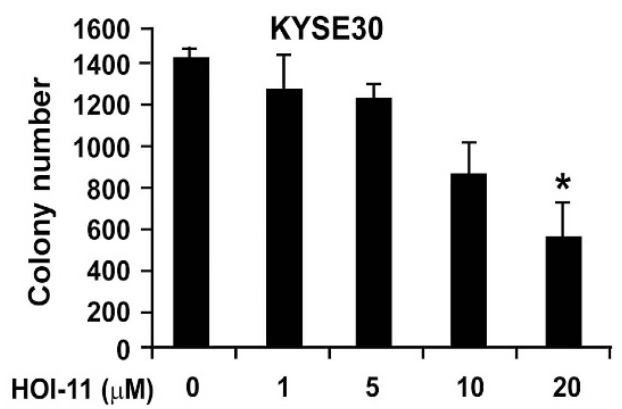

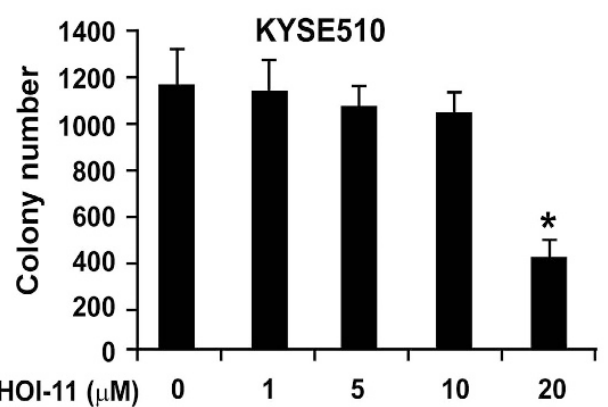

Figure $1 \mathrm{HOI}-02$ decreases viability of esophageal cancer cells and their anchorage-independent growth. (a) Chemical structure of HOI-02 (left panel). HOI-02 decreases KYSE30 (middle panel) and KYSE510 (right panel) esophageal cancer cell viability in a dose-dependent manner. KYSE30 and KYSE510 cells ( $1 \times 10^{3}$ per well) were treated with the indicated doses of $\mathrm{HOI}-02$ for the specified times. The absorbance was measured as described in Materials and methods section. Data are shown as mean values \pm S.D. and the asterisks $\left(^{*},{ }^{* *}\right)$ indicate a significant $(P<0.05, P<0.01$, respectively) decrease in viability of cells treated with $\mathrm{HOI}-02$ compared with untreated control cells. (b) HOI-02 suppresses anchorage-independent growth of esophageal cancer cells. Colony numbers are shown as mean values \pm S.D. from three independent experiments. The asterisks $\left({ }^{*},{ }^{* *}\right)$ indicate a significant $(P<0.05, P<0.01$, respectively) decrease in colony numbers in cells treated with $\mathrm{HOI}-02$ compared with the DMSO-treated group. (c) Chemical structure of HOI-11 (left panel). $\mathrm{HOI}-11$ has no effect on viability of KYSE30 (middle panel) or KYSE510 (right panel) esophageal cancer cells. KYSE30 or KYSE510 cells $\left(1 \times 10^{3}\right.$ per well) were treated with the indicated doses of $\mathrm{HOl}-11$ for the specified times. The absorbance was measured as described in Materials and methods section. Data are shown as mean values \pm S.D. (d) Only the highest dose of $\mathrm{HOl}-11$ suppresses anchorage-independent growth of esophageal cancer cells. Colony numbers are shown as mean values \pm S.D. from three independent experiments. The asterisk $\left(^{*}\right)$ indicates a significant $(P<0.05)$ decrease in colony numbers of cells treated with $\mathrm{HOI}-11$ compared with the DMSO-treated group 

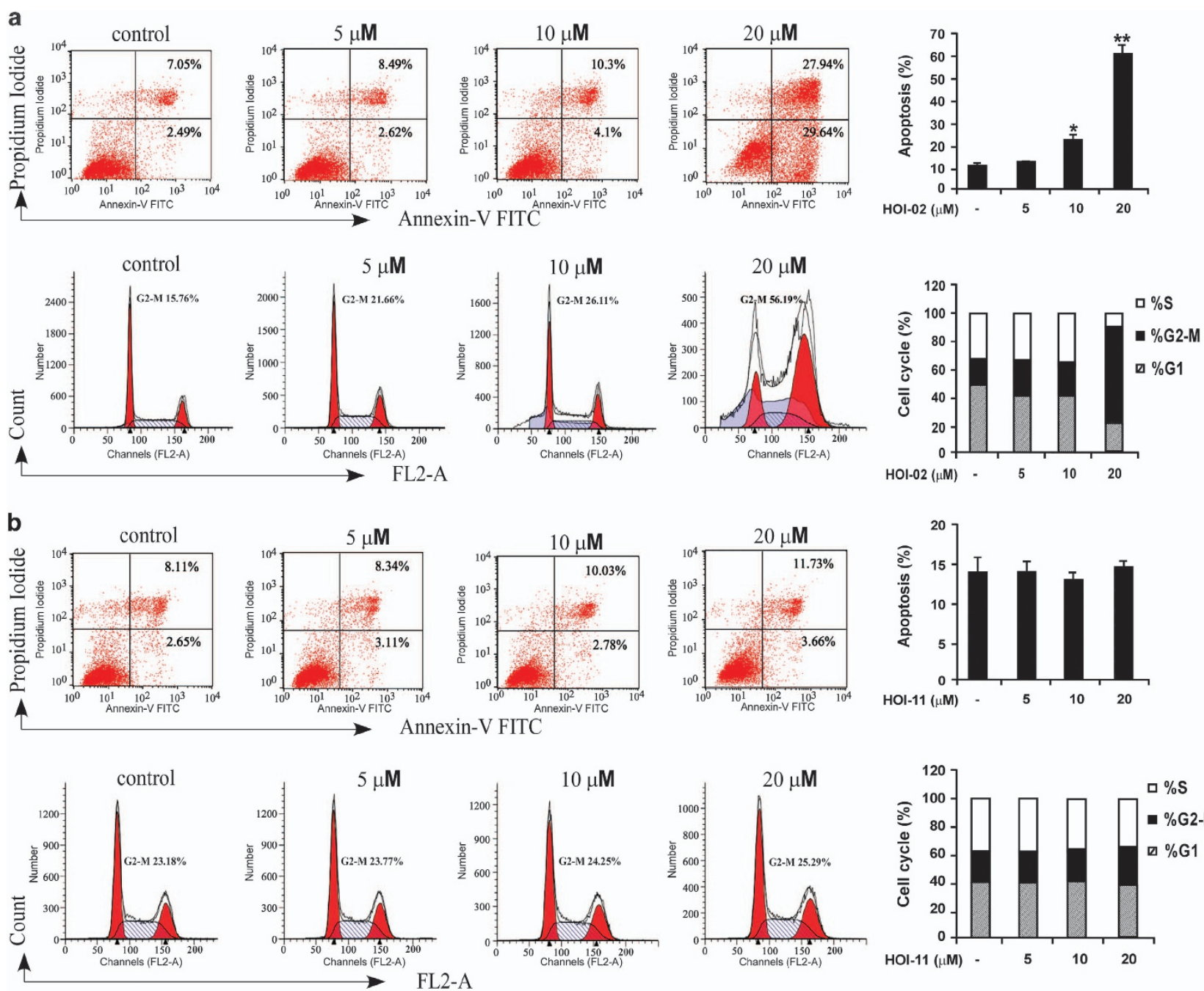

C
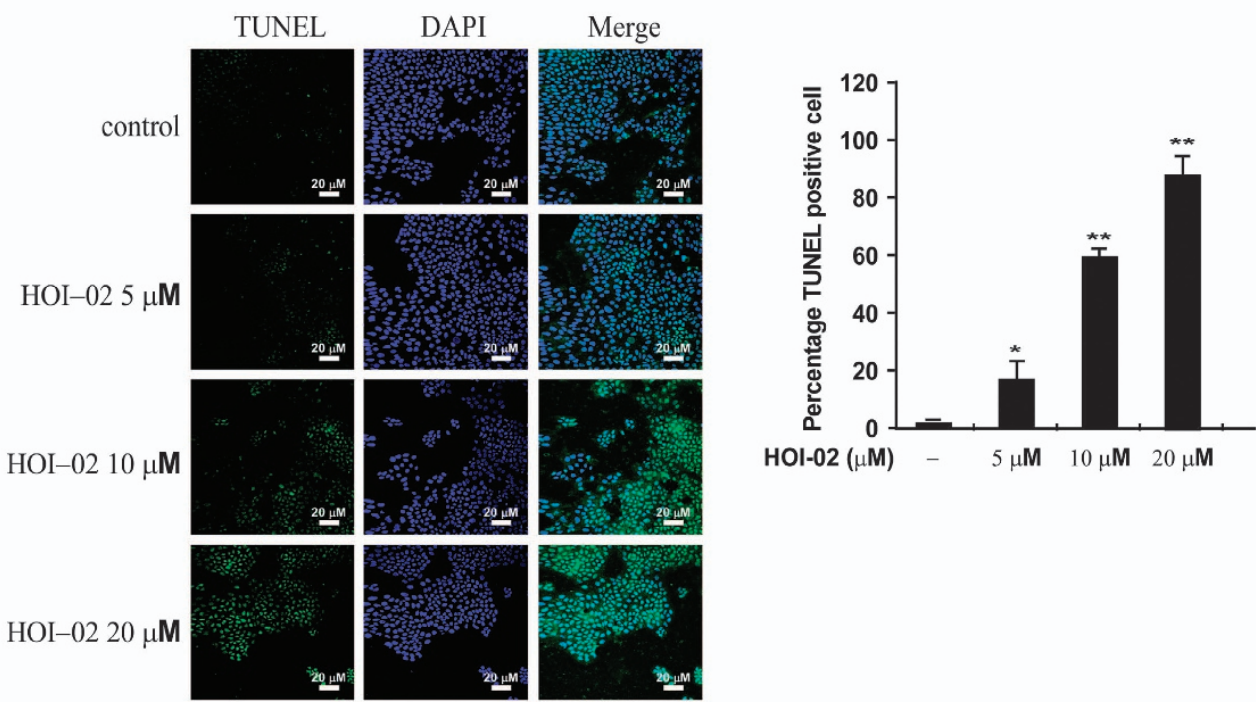

Figure 2 HOl-02 induces apoptosis and G2-M arrest in esophageal cancer cells. (a) Flow cytometry analysis of apoptosis (upper panels) and cell cycle (lower panels) in KYSE510 cells with treatment of HOI-02. Percent apoptosis is shown as mean values \pm S.D. from three independent experiments. The asterisks $\left({ }^{*}\right.$, $\left.{ }^{*}\right)$ indicate a significant $(P<0.05, P<0.01$, respectively) difference in apoptosis in cells treated with HOI-02 compared with the DMSO-treated group. (b) Flow cytometry analysis of apoptosis (upper panels) and cell cycle (lower panels) in KYSE510 cells treated with HOI-11. Percent apoptosis is shown as mean values \pm S.D. from three independent experiments. (c) Immunocytochemical staining of TUNEL-positive cells treated with HOI-02. DAPI was used for counter-staining cells. The experiment was repeated three times and representative results are shown. The asterisks $\left({ }^{*},{ }^{* *}\right)$ indicate a significant $(P<0.05, P<0.01$, respectively) increase in TUNEL-positive cells 
a
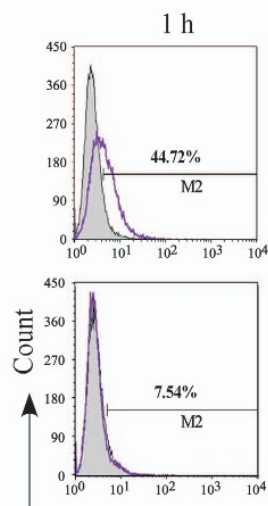

$3 \mathrm{~h}$
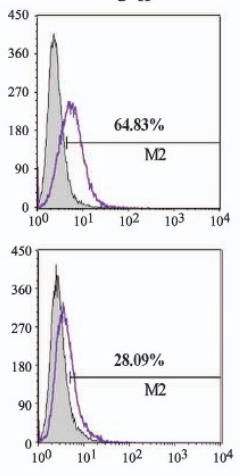

$6 \mathrm{~h}$
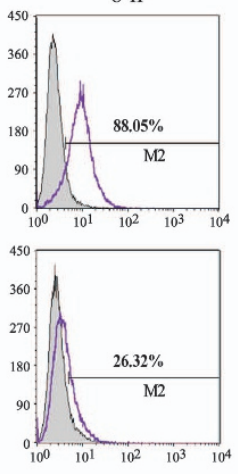
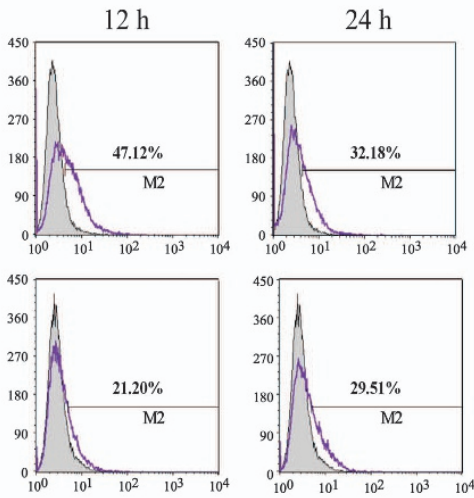

b

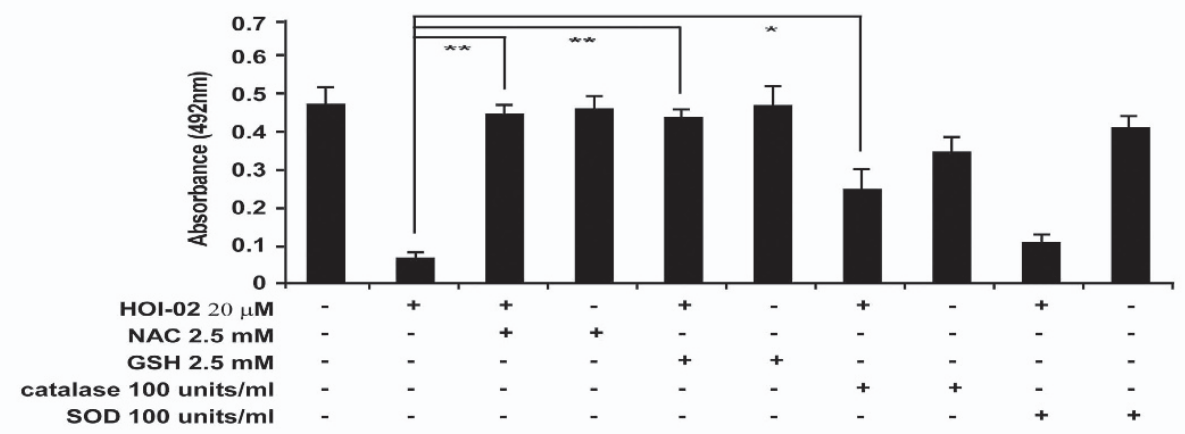

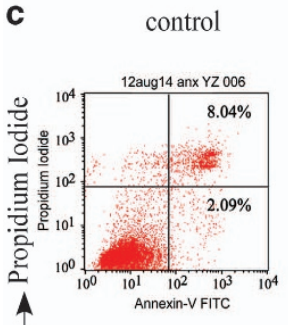

control

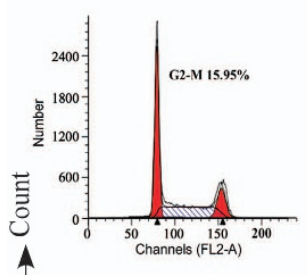

$20 \mu$ M HOI-02

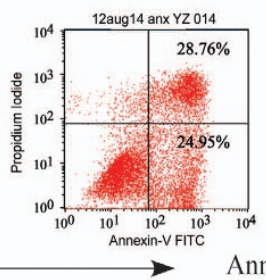

$20 \mu \mathrm{M}$ HOI-02

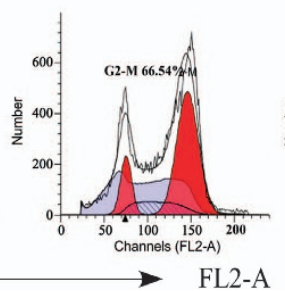

$20 \mu \mathrm{M}$ HOI-02 + 2.5 mM NAC

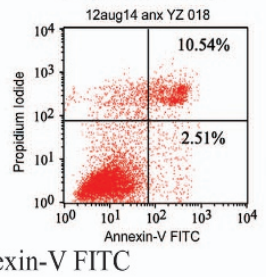

$20 \mu \mathrm{M}$ HOI-02 + $2.5 \mathrm{mM}$ NAC

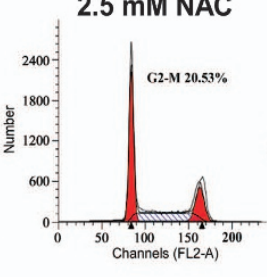

$2.5 \mathrm{mM}$ NAC

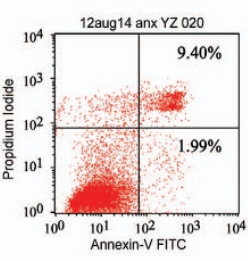

$2.5 \mathrm{mM}$ NAC

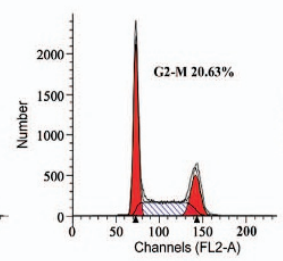

$20 \mu \mathrm{M} \mathrm{HOI-02+}$ $2.5 \mathrm{mM}$ GSH

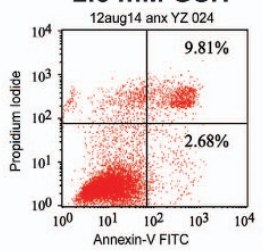

$20 \mu \mathrm{M} \mathrm{HOI}-02+$ $2.5 \mathrm{mM}$ GSH

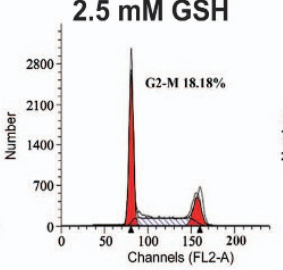

control

HOI-11 $20 \mu \mathrm{M}$

control

HOI-02 $20 \mu \mathrm{M}$

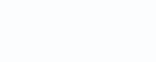

Figure 3 ROS are involved in HOI-02-induced apoptosis and G2-M arrest of esophageal cancer cells. (a) KYSE510 cells were treated with $20 \mu \mathrm{M} \mathrm{HOI-02} \mathrm{for} \mathrm{the} \mathrm{indicated}$ times and the production of intracellular ROS was detected by flow cytometry using DCFH-DA. (b) HOI-02 decreases viability of KYSE510 esophageal cancer cells even in the presence of SOD, but not with NAC or GSH. KYSE510 cells $\left(1 \times 10^{3}\right.$ per well) were treated as indicated for $24 \mathrm{~h}$. The absorbance was measured as described in Materials and methods section. Data are shown as mean values \pm S.D. and the asterisks $\left({ }^{*}\right.$, $\left.{ }^{* *}\right)$ indicate a significant $(P<0.05, P<0.01$, respectively) decrease in viability of treated cells compared with the untreated control cells. (c) KYSE510 esophageal cancer cells $\left(5 \times 10^{5}\right)$ were treated with $20 \mu \mathrm{M} \mathrm{HOI}-02$ for $24 \mathrm{~h}$ with or without $2.5 \mathrm{mM}$ NAC or GSH. Apoptosis (upper panels) and cell cycle (lower panels) were analyzed by flow cytometry

several proteins known to be associated with G2-M phase in KYSE510 cells. We found that phosphorylation of Cdc2 (Tyr15), ATR (Ser428), ATM (Ser1981), H2AX (Ser139), p53 (Ser15) and total p21 were increased, whereas phosphorylation of cyclin B1 (Ser147) was decreased with HOI-02 treatment (Figure 6a). These changes in protein expression could result in G2-M arrest. We also examined the effect of $\mathrm{HOl}-02$ treatment with and without NAC or GSH and found that the increases in phosphorylation of Cdc2 (Tyr15), H2AX (Ser139) and total p21 were attenuated when GSH or NAC was included in the reaction (Figure 6b). Overall, our results in esophageal cancer cells treated with $\mathrm{HOl}-02$ suggest that 
a

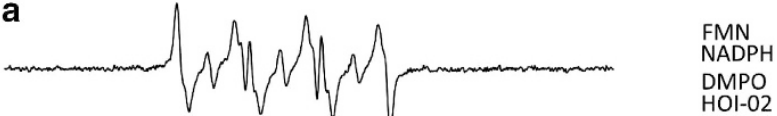

b

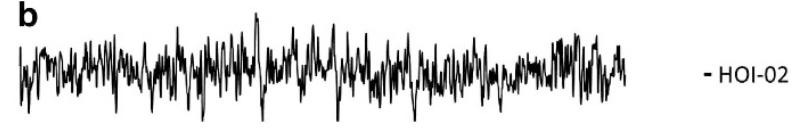

C

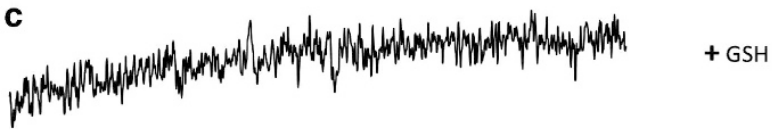

d

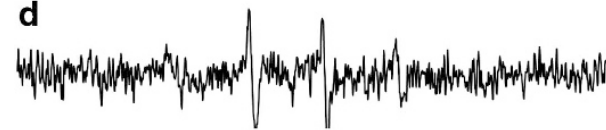

+ Catalase

e

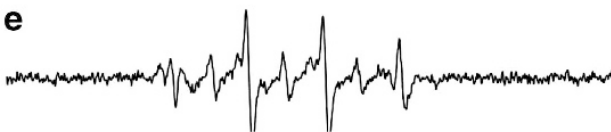

+ SOD

f

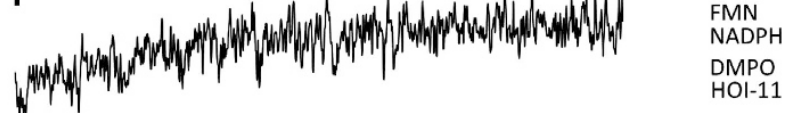

Figure 4 EPR signals generated by DMPO spin adducts in the HOI-02/NADPH/ FMN system. EPR spectra were obtained from incubation mixtures containing

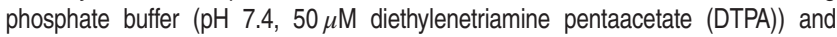
100 mM DMPO: (a) HOI-02 (20 $\mu \mathrm{M})$, DMPO (100 mM), NADPH (0.4 mM) and FMN $(7 \mu \mathrm{M})$. (b) Same as a, but without compound HOI-02. (c) Same as a, but with $2.5 \mathrm{mM}$ GSH. (d) Same as a, but with 100 units/ml of catalase. (e) Same as a, but with 100 units/ml of SOD. (f) Same as a, but compound HOI-02 is replaced with HOI-11

ROS activate AP-1 and cleaved caspase 3, which contribute to apoptosis, and also p21 signaling, which participates in G2-M arrest (Figure 6c).

HOI-02 suppresses tumor growth in vivo by generating ROS and activating AP-1, caspase 3 and p21 signaling. We evaluated the effect of HOl-02 on growth of esophageal cancer patient-derived xenograft (PDX) growth. Treatment of mice with $\mathrm{HOI}-02$ reduced tumor weight dose dependently compared with the untreated control (Figure 7a; $P<0.01$ ) and the mean tumor volume in the vehicle-treated group increased faster than that in the HOl-02-treated group (Figure $7 \mathrm{~b} ; P<0.01$ ). Moreover, immunohistochemical analysis of tumors showed that the expression of Ki-67, a cell proliferation marker, was markedly decreased and phosphorylation of c-Jun (Ser63) and expression of total p21 and cleaved caspase 3 were increased in tumors treated with HOl-02 compared with the untreated controls (Figure 7c). In addition, immunofluorescence results show that DCFH-DA was significantly increased in $\mathrm{HOI}-02$-treated tumors compared with the controls (Figure 7d), which indicates the presence of ROS. Collectively, these findings provide evidence supporting the idea that the anticancer efficacy of $\mathrm{HOI}-02$ is mediated in vivo by generation of ROS resulting in increased cleavage of caspase 3 , induction of AP-1 and enhanced p21 signaling, all of which contribute to the inhibition of esophageal cancer cell growth.

\section{Discussion}

Accumulating evidence suggests that many types of cancer cells exhibit increased levels of ROS. ${ }^{9}$ ROS, like hydrogen peroxide $\left(\mathrm{H}_{2} \mathrm{O}_{2}\right)$ and others, can act as second messengers in cellular signaling. ${ }^{12,13}$ ROS regulate protein activity through reversible oxidation of proteins such as tyrosine phosphatases, tyrosine kinases, transcription factors and receptor tyrosine kinases. ${ }^{14,15}$ In this study, we found that $\mathrm{HOI}-02$, which contains an $\mathrm{NO}_{2}$ group, could increase the generation of $\mathrm{ROS}$ in esophageal cancer cells. The nitro group in $\mathrm{HOI}-02$ can undergo enzymatic one-electron reduction to form a nitro radical anion and one-electron reduction has been described in microsomes and mitochondria and with purified enzymes. ${ }^{16}$ Under aerobic conditions, molecular oxygen oxidizes the nitro anion radical, resulting in a redox cycle with regeneration of the nitro compound and production of superoxide anion, whose dismutation yields $\mathrm{H}_{2} \mathrm{O}_{2}$ (Ask et al. ${ }^{17}$ ) (Supplementary Figure $\mathrm{S2C}$ ). Our data indicated that $\mathrm{H}_{2} \mathrm{O}_{2}$ is the most likely ROS species generated by $\mathrm{HOI}-02$ against esophageal cancer cell growth. As shown in the Figures $3 \mathrm{~b}$ and c, GSH, but not SOD, could significantly inhibit cell viability, apoptosis and G2-M arrest. Also, as shown in Figure 4, we found that GSH or catalase, but not SOD, could significantly decrease the radical signal. The sensitivity to catalase indicates that the radical signal is likely derived from $\mathrm{H}_{2} \mathrm{O}_{2}$. In addition, the generation of other free radicals such as $\mathrm{NO}$ and $\mathrm{NO}_{2}$ was not detected with EPR and iNOS was also not induced with $\mathrm{HOI}-02$ treatment as indicated by western blot analysis. These studies indicate that ROS have a significant role of $\mathrm{HOI}-02$ treatment in esophageal cancer cells.

Induction of apoptosis has been a key strategy for cancer therapy. Successful apoptosis-inducing anticancer drugs cause tumor cells to die by either directly turning on pro-apoptotic pathways or turning off anti-apoptotic pathways. ${ }^{18}$ ROS have an important role in inducing apoptosis under both physiological and pathological conditions. ${ }^{19-22}$ ROS are known to cause apoptosis both through caspase-dependent and caspase-independent cell signaling cascades. $^{23,24}$ Apoptotic cell death has traditionally been associated with caspase activation. The released apoptotic proteins initiate caspase activation and trigger caspase-mediated apoptotic DNA fragmentation and eventually cell death. In this study, we showed that $\mathrm{HO} 1-02$ induced caspase 3 and PARP cleavage (Figure 5a). JNKs are one of the major signaling molecules that are activated through the caspase-independent pathway. ${ }^{25}$ After activation by ROS, JNKs can stimulate AP-1, a transcription factor consisting of dimers of the Fos and Jun families of proteins. The activation of AP-1 appears to be at least partially responsible for apoptosis stimulated by $\mathrm{HOI}-02$ (Figure 5d). AP-1 luciferase activity or phosphorylation of Fos and Jun induced by HOI-02 was attenuated by GSH or NAC, suggesting that $\mathrm{HOI}-02$ induces esophageal cancer cell apoptosis through the generation of ROS.

Cancer progression is believed to involve the loss of checkpoint controls that regulate normal passage through the cell cycle. By supplementing existing cell cycle machinery with extrinsic cell cycle regulators, blocking initiation or progression of cancer may be possible. HOl-02 treatment caused G2-M cell cycle arrest, which could be beneficial in 
a

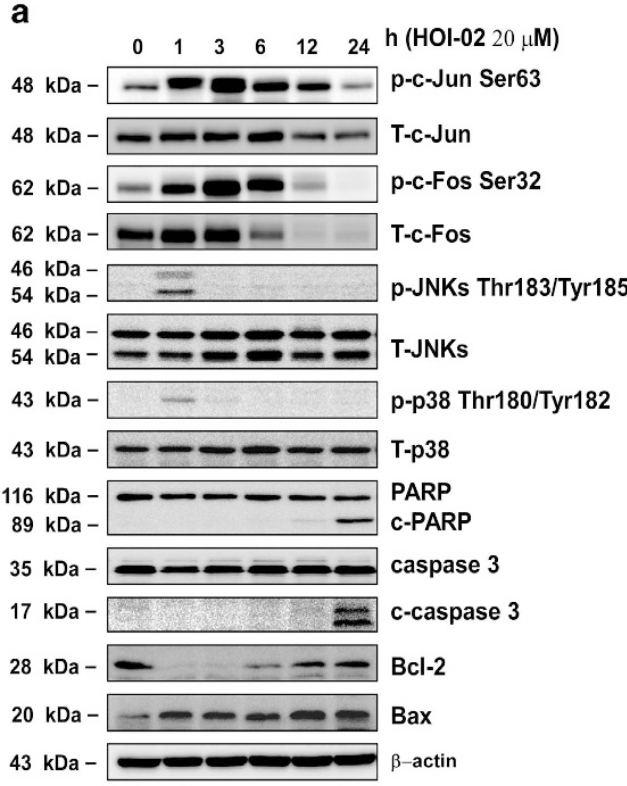

b

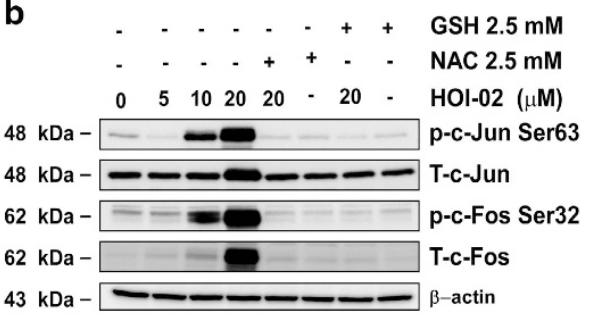

C

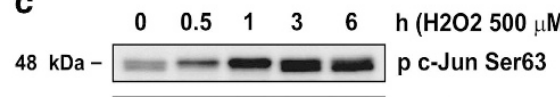

$48 \mathrm{kDa}-\longrightarrow$ T-C-Jun

$62 \mathrm{kDa}-\square \mathrm{p}-\mathrm{p}-\mathrm{C}-$ Fos Ser32

$62 \mathrm{kDa}-\square$ T-C-Fos

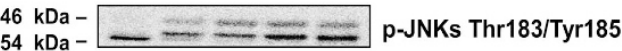

$46 \mathrm{kDa}-\square-\square=\square-J N K s$

$43 \mathrm{kDa}-\mathrm{p}$-p38 Thr180/Tyr82

$43 \mathrm{kDa}-\longrightarrow$ T-p38

$43 \mathrm{kDa}-\longrightarrow \beta-$ actin

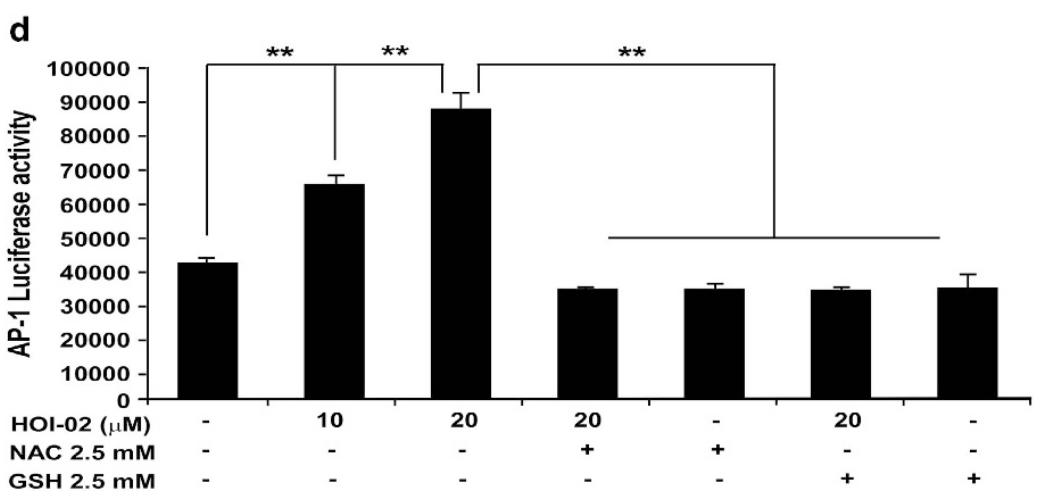

Figure 5 HOI-02-induced apoptosis is mediated through induction of AP-1 activity and the modulation of caspase expression. (a) KYSE510 cells $\left(1 \times 10^{6}\right)$ were treated with $20 \mu \mathrm{M} \mathrm{HOI}-02$ for the indicated times. The expression of apoptosis-related proteins was determined by western blot analysis using specific antibodies. $\beta$-Actin was detected in the same membrane and served as a loading control. Data shown are representative of results from triplicate independent experiments. (b) KYSE 510 cells $\left(1 \times 10^{6}\right)$ were treated with various doses of $\mathrm{HOI}-02(0,5,10$ or $20 \mu \mathrm{M}), 2.5 \mathrm{mM} \mathrm{NAC}$ or $2.5 \mathrm{mM} \mathrm{GSH}$ for $24 \mathrm{~h}$. The expression of proteins was determined by western blot analysis using specific antibodies. (c) ROS induce phosphorylation of c-Jun and c-Fos in esophageal cancer cells. After treatment with $500 \mu \mathrm{M} \mathrm{H}_{2} \mathrm{O}_{2}$ for the indicated times, the expression of proteins was determined by western blot analysis using specific antibodies. (d) HOI-02 induces AP-1 luciferase activity and the effect is blocked by NAC or GSH in KYSE510 esophageal cancer cells. KYSE510 cells were transiently transfected with the AP-1 luciferase reporter gene construct and incubated with $\mathrm{HOI}-02(0,10$ or $20 \mu \mathrm{M}), 2.5 \mathrm{mM} \mathrm{NAC}$ or $2.5 \mathrm{mM}$ GSH. Luciferase activity was measured as described in Materials and methods section

suppressing the progression of esophageal cancer (Figure 2a, lower panels). We observed that HOI-02 activated the ATM/ p53-p21 signaling network (Figure 6a), which has been implicated in G2-M cell arrest. ${ }^{26}$ Generally, the activation of ATR is considered as a consequence of the formation of single-stranded DNA. ${ }^{27}$ The generation of single-stranded DNA in re-replicated cells may account for the induction of the G2-M checkpoint mediated by ATR. DNA re-replication continues as the cells are arrested in G2-M phase. ${ }^{28}$ In contrast, activation of ataxia telangiectasia mutated (ATM) is observed mostly in cells with double-stranded DNA breaks ${ }^{27}$ and is one of the proteins activated by ROS that is involved in cell cycle regulation. ${ }^{14}$ The mitogen-activated protein kinases (MAPKs), p38 and JNKs, have been implicated in apoptotic signaling in response to increased generation of ROS. ${ }^{29}$
Histone $\mathrm{H}_{2} \mathrm{AX}$ phosphorylation on Ser139 in response to DNA damage involves formation of DNA double-strand breaks. ${ }^{30,31}$ This phosphorylation is mediated by ATM and ATR and was also triggered by $\mathrm{HOI}-02$ and disappeared when cells were treated with $\mathrm{GSH}$ or NAC in combination with $\mathrm{HOI}-02$ (Figure 6b).

For many years, mouse xenograft models implanted with human cancer cells lines have been used extensively for predicting responsiveness to anticancer target agents. In contrast, PDXs are based on the transfer of primary tumors directly from the human patient into an immune-deficient mouse. PDX models may be superior to traditional cell line xenograft models of cancer because they maintain more similarities to the parental tumors. ${ }^{32}$ PDX models also provide an invaluable assessment of tumor evolution and adaptive 
a

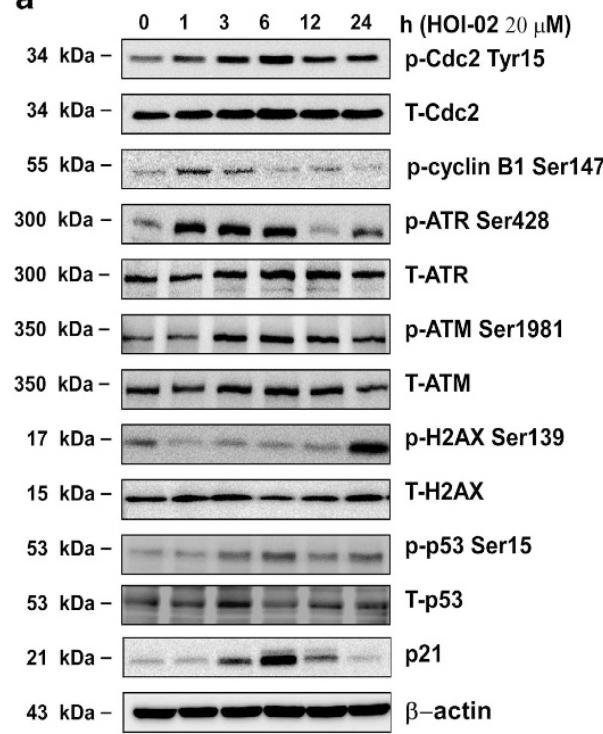

b

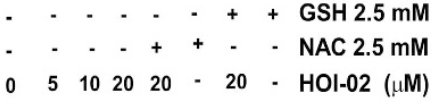

$34 \mathrm{kDa}-\ldots-\ldots-\mathrm{p}-\mathrm{Cdc} 2 \mathrm{Tyr} 15$

$34 \mathrm{kDa}-(-----1 \mathrm{~T}-\mathrm{Cdc} 2$

$17 \mathrm{kDa}-$

$15 \mathrm{kDa}-$

$21 \mathrm{kDa}-\square$ p21

$43 \mathrm{kDa}-\longrightarrow \beta$-actin

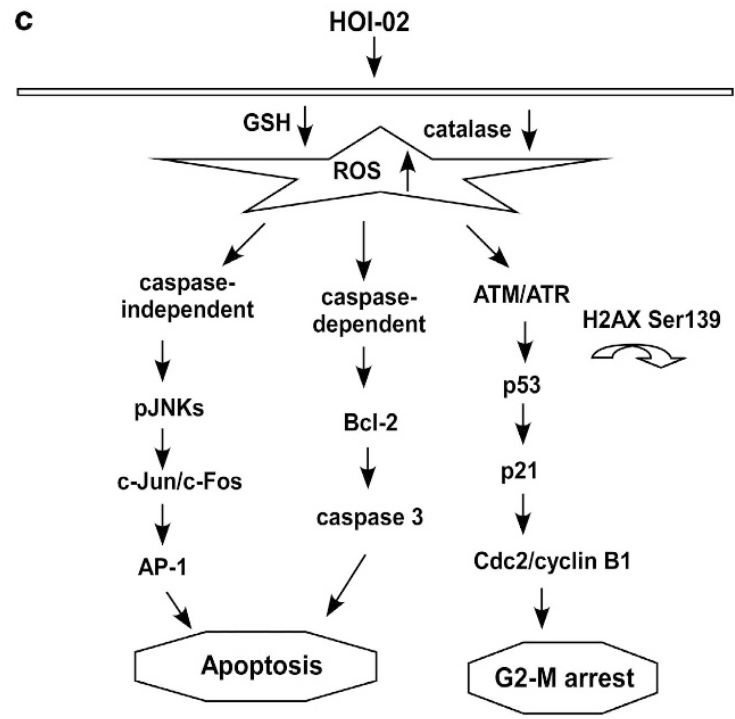

Figure 6 HOI-02-induced G2-M arrest is mediated through a p21-related pathway. (a) KYSE510 cells $\left(1 \times 10^{6}\right)$ were treated with $20 \mu \mathrm{M} \mathrm{HOI-02} \mathrm{for} \mathrm{the} \mathrm{indicated} \mathrm{times.} \mathrm{The}$ expression of cell cycle-related proteins was determined by western blot analysis using specific antibodies. $\beta$-Actin was detected in the same membrane and served as a loading control. Data shown are representative of results from triplicate independent experiments. (b) KYSE510 cells $\left(1 \times 10^{6}\right)$ were treated with various doses of HOI-02 $(0,5,10$ or $20 \mu \mathrm{M}), 2.5 \mathrm{mM}$ NAC or $2.5 \mathrm{mM} \mathrm{GSH}$ for $24 \mathrm{~h}$. The expression of proteins was determined by western blot analysis using specific antibodies. (c) A proposed model of the mechanisms of apoptosis and G2-M phase arrest induced by HOI-02 in esophageal cancer cells

response to therapy. ${ }^{33}$ In this study, $\mathrm{HOI}-02$ consistently and significantly inhibited growth of patient-derived esophageal cancers in nude mice (Figures $7 a$ and $b$ ). Tissue samples from tumors treated with $\mathrm{HOI}-02$ showed more intense staining with DCFH-DA compared with the untreated control (Figure 7d). Taken together, our cell-based studies and in vivo studies support the concept that $\mathrm{HOI}-02$ treatment could effectively inhibit esophageal cancer cell growth by inducing apoptosis and cell cycle arrest.

\section{Materials and Methods}

Reagents and antibodies. RPMI-1640 medium and fetal bovine serum (FBS) were from Mediatech, Inc. (Manassas, VA, USA), N-acetyl cysteine (NAC), catalase, SOD and HiQ Standard Agarose were purchased from Sigma-Aldrich (St. Louis, MO, USA). Glutathione (GSH), DMPO, 2,7-dichlorodihydrofluorescein diacetate (DCFH-DA) and NADPH were obtained from Cayman Chemical (Ann Arbor, MI, USA). FMN was from TCI AMERICA (Portland, OR USA). Antibodies to detect total c-Jun, phosphorylated c-Jun (Ser63), total c-Fos, phosphorylated c-Fos (Ser32), total JNKs, phosphorylated JNKs (Thr183/Tyr185), total p38, phosphorylated p38 (Thr180/Tyr182), total ATR, phosphorylated ATR (Ser428), phosphorylated ATM (Ser1981), total H2AX, phosphorylated H2AX (Ser139), total p53, phosphorylated p53 (Ser15), total CDC2, phosphorylated CDC2 (Tyr15), phosphorylated cyclin B1 (Ser147), caspase 3 (Asp175), PARP, cleaved PARP (Asp214) and iNOS were purchased from Cell Signaling Technology, Inc. (Danvers, MA, USA). The antibodies to detect total ATM, Bax and p21 were obtained from Santa Cruz Biotechnology, Inc. (Santa Cruz, CA, USA).

Cell culture. The KYSE510, KYSE30 and KYSE450 human esophageal cancer cell lines were cultivated in RPMI-1640 media supplemented with $10 \%$ heatinactivated FBS. All cells used in these studies were maintained with antibiotics at $37^{\circ} \mathrm{C}$ in a $5 \% \mathrm{CO}_{2}$ humidified incubator according to American Type Culture 
a
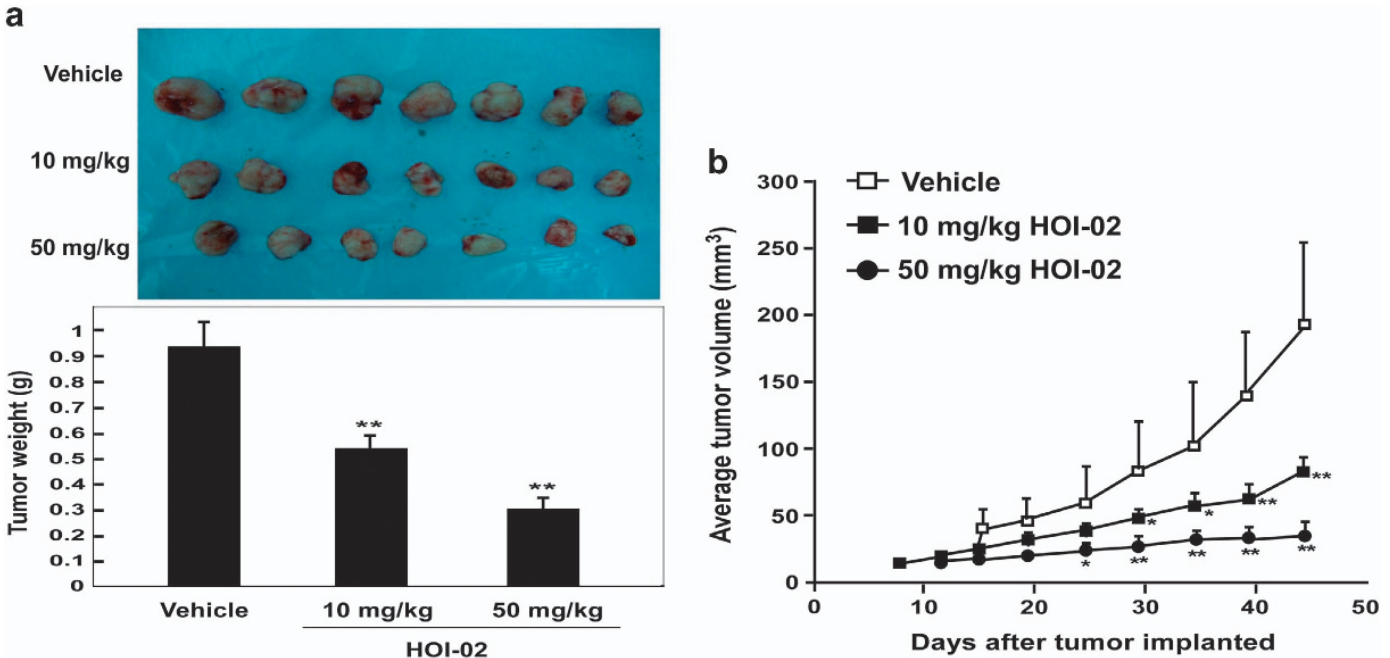

C
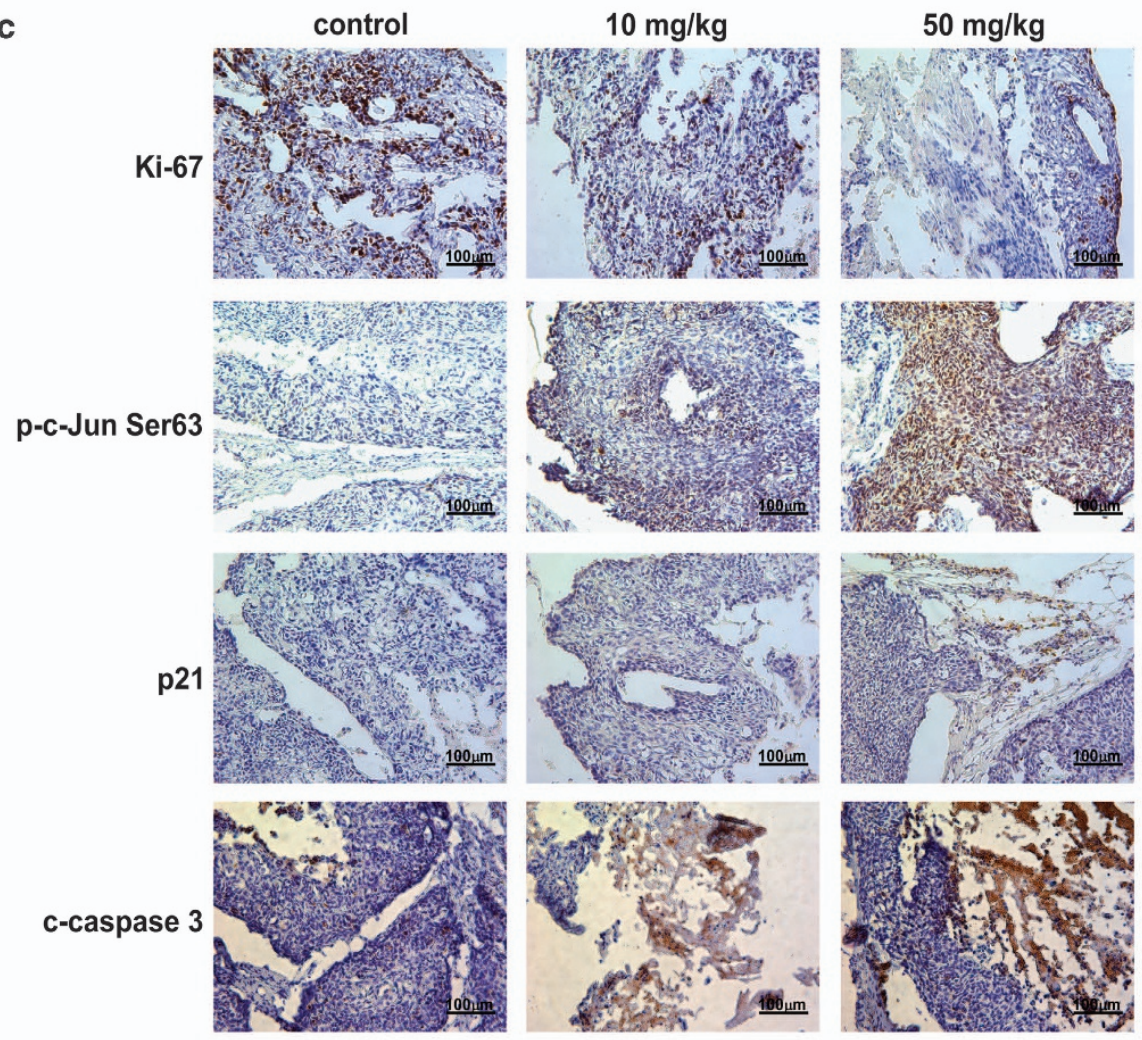

d
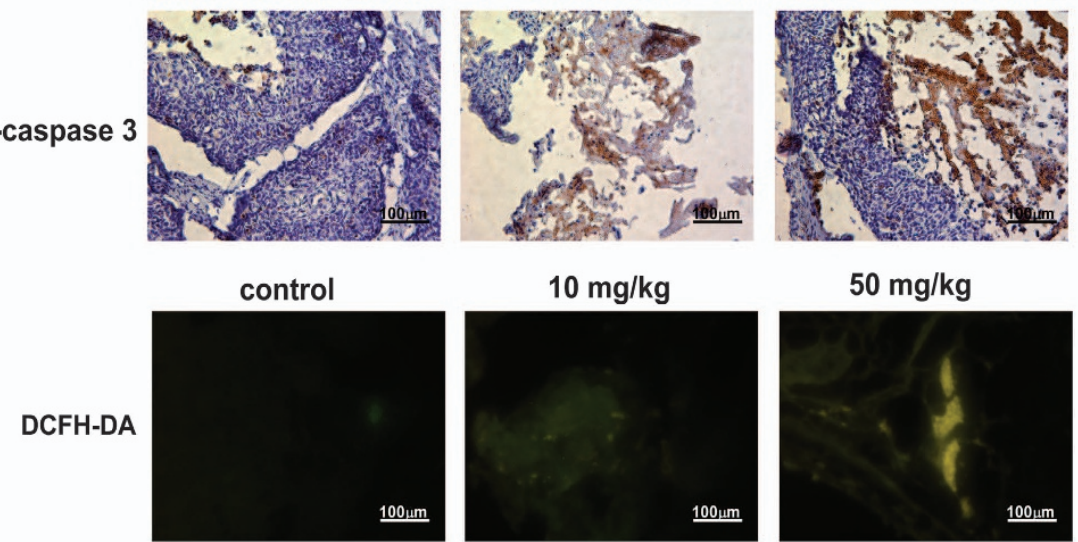

Figure 7 HOI-02 suppresses tumor growth in vivo by generation of ROS and activation of AP-1, cleaved caspase 3 and p21. (a) The total average tumor weight in the HOI-02treated group is significantly less than that of the vehicle-treated group. Tumors were extracted and weighed after mice were killed. Data are shown as mean values \pm S.D. The asterisks $\left.{ }^{* *}\right)$ indicate a significant decrease in tumor weight $(P<0.01)$ in the $\mathrm{HOI}-02$-treated group compared with the vehicle-treated group. (b) $\mathrm{HOI}-02$ treatment suppresses tumor volume compared with the vehicle-treated group. Tumor volume was measured and recorded as described in Materials and methods section. The asterisks $\left({ }^{*}\right.$, **) indicate a significant decrease in tumor size $(P<0.05, P<0.01$, respectively) in the HOI-02-treated group compared with the vehicle group. (c) Immunohistochemical analysis of tumor tissues. Treated or untreated groups of mice were euthanized and tumors extracted. Esophageal cancer tissue slides were prepared with paraffin sections after fixation with formalin and then stained to detect the indicated proteins. (d) Fluorescent microscopic observation of sections stained with DCFH-DA, which reflects the level of ROS in the tissues 
Collection protocols (ATCC, Manassas, VA, USA). Cells were crytogenetically tested and authenticated before being frozen. Each vial of frozen cells was thawed and maintained for a maximum of 20 passages.

MTS assay. KYSE510 or KYSE30 cells $\left(1 \times 10^{3}\right)$ were seeded into 96-well plates in $100 \mu \mathrm{l}$ of $10 \% \mathrm{FBS} / \mathrm{RPMI}-1640$ medium and incubated at $37^{\circ} \mathrm{C}$ in a $5 \%$ $\mathrm{CO}_{2}$ humidified incubator. After culturing for $12 \mathrm{~h}$, different concentrations of $\mathrm{HOI}-02$ or $\mathrm{HOl}-11$ and NAC, GSH, catalase, or SOD were added to each well. After incubation for another 24, 48, 72 or $96 \mathrm{~h}, 20 \mu \mathrm{l}$ of the CellTiter 96 Aqueous One Solution (Promega, Madison, WI, USA) were added to each well and cells were then incubated for an additional $1 \mathrm{~h}$ at $37^{\circ} \mathrm{C}$. Absorbance was measured at an optical density of $490 \mathrm{~nm}$ using the Thermo Multiskan plate-reader (Thermo Fisher Scientific, Waltham, MA, USA).

Western blot analysis. Cellular proteins were extracted using cell lysis buffer ( $150 \mathrm{mM} \mathrm{NaCl}, 0.25 \%$ sodium deoxycholate, $50 \mathrm{mM}$ Tris-HCl pH 8.0, 1\% Nonidet P- $40,0.1 \%$ sodium dodecyl sulfate (SDS), $1 \mathrm{mM}$ EDTA and protease inhibitor mixture). Protein concentration was measured using a protein assay kit (Bio-Rad, Hercules, CA, USA) and proteins were subjected to $10 \%$ SDS/polyacrylamide gel electrophoresis (PAGE). Proteins were then transferred onto polyvinylidene difluoride (PVDF) membranes (Amersham Biosciences, Piscataway, NJ, USA) and hybridized with the appropriate specific primary antibody and a horseradish peroxidase-conjugated secondary antibody. Antibody binding was conducted at $4{ }^{\circ} \mathrm{C}$ overnight and proteins were visualized using an enhanced chemiluminescence reagent and the ImageQuant LAS4000 system (GE Healthcare, Piscataway, NJ, USA).

Flow cytometry analysis. KYSE510 cells were plated in 10-cm dishes and treated with vehicle (DMSO only), $\mathrm{HOI}-02$ or $\mathrm{HOl}-11$ for $24 \mathrm{~h}$. Cells were then harvested and washed with PBS and subsequently stained with Annexin V-FITC and propidium iodide (MBL International Corp., Woburn, MA, USA). Cell cycle distribution or apoptosis was determined using the FACSCalibur flow cytometer (BD Biosciences, San Jose, CA, USA).

Measurement of intracellular ROS by flow cytometry. After treatment for different times with $\mathrm{HOI}-02$ or HOI-11, DCFH-DA was added to cells at a final concentration of $10 \mu \mathrm{M}$. Cells were incubated at $37^{\circ} \mathrm{C}$ in a $5 \% \mathrm{CO}_{2}$ humidified incubator for $30 \mathrm{~min}$. Cells were then washed with PBS, collected by centrifugation and analyzed on the FACSCalibur flow cytometer (BD Biosciences).

EPR measurements. All EPR measurements were conducted using a Bruker EleXsys E500 spectrometer (Billerica, MA, USA) equipped with an ER 4122 SHQ spherical resonator (Billerica, MA, USA). The WACY Software program was used for data baseline subtraction and data acquisition (Edmund Howard, Dave Thomas lab, University of Minnesota, Minneapolis, MN, USA). Reactants were mixed in test tubes in a final volume of $20 \mu \mathrm{l}$, and then transferred to capillary $(0.6 / 0.84 \mathrm{~mm}$ ID/OD, Vitrocom, Mountain Lakes, NJ, USA) assemblies for EPR measurement. The concentrations shown in the figure legends are final concentrations. All experiments were performed at room temperature and under ambient air except those as specifically indicated. Spectra were acquired with the following parameters: $2 \mathrm{~mW}$ microwave power, $1 \mathrm{G}$ peak-to-peak modulation amplitude, $120 \mathrm{G}$ sweep width and $40.96 \mathrm{~ms}$ time constant and conversion time.

TUNEL assay. KYSE510 cells $\left(2 \times 10^{4}\right)$ were seeded into four-chamber polystyrene vessel tissue culture glass slides (BD Biosciences) in $500 \mu \mathrm{l} 10 \% \mathrm{FBS} /$ RPMI-1640 medium and incubated at $37^{\circ} \mathrm{C}$ in a $5 \% \mathrm{CO}_{2}$ humidified incubator. After culturing for $24 \mathrm{~h}$, different concentrations of $\mathrm{HOI}-02$ were added to each chamber. After incubation for another $24 \mathrm{~h}$, cells were fixed in $4 \%$ paraformaldehyde in PBS for $25 \mathrm{~min}$ at room temperature $\left(25^{\circ} \mathrm{C}\right)$. Cells were washed three times in PBS for 10 min each time and then stained using the DeadEnd Fluorometric TUNEL System (Promega) according to the manufacturer's protocol. All of the samples were counterstained with 4',6-diamidino-2-phenylindole (DAPI). The number of TUNELpositive cells was determined by laser scanning confocal microscopy (Nikon $\mathrm{C}^{\mathrm{s} 1}$ Confocal Spectral Imaging System, Nikon Instruments Co., Melville, NY, USA) using a CFI Plan Fluor $\times 20$ objective and then analyzed using the EZ-C1 (v3.20) software program (Nikon).

Anchorage-independent growth assay. KYSE30, KYSE450 and KYSE510 cells $\left(8 \times 10^{3}\right.$ per well) were suspended in $1 \mathrm{ml}$ Basal medium Eagle
(BME), $10 \% \mathrm{FBS}$, and $0.33 \%$ agar and plated with various concentrations of $\mathrm{HOI}-02$ or $\mathrm{HOl}-11$ on $3 \mathrm{ml}$ of solidified BME containing $10 \% \mathrm{FBS}$ and $0.5 \%$ agar with different concentrations of $\mathrm{HOI}-02$ or $\mathrm{HOI}-11$. Cells were incubated for 12 days and then colony number was determined by microscope and the Image-Pro Plus software (v. 6.1) program (Media Cybernetics, Inc., Rockville, MD, USA).

Reporter gene activity. KYSE510 cells $\left(5 \times 10^{4}\right.$ per well) were seeded into 12-well dishes and incubated for $24 \mathrm{~h}$. Cells were transfected with the AP-1 reporter plasmid $(800 \mathrm{ng}$ ) and incubated for $36 \mathrm{~h}$ and then treated with $\mathrm{HOI}-02$, NAC or GSH for $24 \mathrm{~h}$. Firefly luciferase activities were measured using substrates provided in the reporter assay system (Promega). Transfection efficiency was normalized with a Renilla plasmid as an internal control.

In vivo PDX model. Esophageal cancer tissue was collected from a 64-yearold male patient diagnosed with moderate esophageal cancer stage TNM T2NOMO Ila. This study was approved by the Ethics Committee of Zhengzhou University and the patient whose tumor sample was used in the study was completely informed and gave full consent. PDX models were initiated by subcutaneous implantation of this patient's esophageal cancer fragments $(\sim 2-3 \mathrm{~mm})$ coated in Matrigel and implanted through subcutaneous flap incisions. All treatment experiments were performed in C.B-17 severe combined immunodeficient mice, 4 to 6 weeks old at time of PDX injection/implantation. Once tumor volumes reached approximately $150 \mathrm{~mm}^{3}$, mice were randomized to treatment with intraperitoneal (i.p.) injections of vehicle or HOI-02. HOI-02 was freshly prepared before each treatment and protected from light before injection. The first group (10 mice) received $100 \mu \mathrm{l}$ of vehicle only ( $2 \%$ DMSO and $5 \%$ Tween-20 in PBS) i.p. every other day for 6 consecutive weeks. The other two groups (10 mice per group) were given $100 \mu \mathrm{l}$ of $\mathrm{HOI}-02$ (dissolved in 2\% DMSO and 5\% Tween-20 in PBS) i.p. every other day at a dose of 10 or $50 \mathrm{mg} / \mathrm{kg}$ body weight for 6 consecutive weeks. Tumor volume (length $\times$ width $\times$ depth $\times 0.52$ ) was measured and body weights were recorded every week. At the end of the study, xenograft tumors were weighed and frozen in liquid nitrogen or fixed in $10 \%$ formalin and embedded in paraffin for histological studies.

Immunohistochemistry analysis. Tumor tissues were embedded in paraffin and subjected to immunohistochemistry. Tissues were deparaffinized and hydrated and then permeabilized with $0.5 \%$ Triton X-100/1 xPBS for $10 \mathrm{~min}$. Tissues were hybridized with primary antibodies to detect Ki-67 (1:100), phosphorylated c-Jun (1:50), cleaved caspase $3(1: 100)$ or p21 and then with biotinylated goat anti-rabbit $\lg G$ or biotinylated goat anti-mouse $\lg G$ for p21 $(1: 25)$ as the secondary antibodies. An ABC kit (Vector Laboratories, Inc., Burlingame, CA, USA) was used to detect protein targets according to the manufacturer's instructions. After developing with 3,30-diaminobenzidine, the sections were counterstained with hematoxylin and analyzed by microscope $(200 x)$ and the Image-Pro Plus software (v. 6.1) program (Media Cybernetics, Inc.).

DCFH-DA staining. To determine the level of ROS, histologic sections of esophageal cancers were stained with DCFH-DA $(10 \mu \mathrm{M})$ in PBS for $30 \mathrm{~min}$. Samples were then rinsed, mounted and analyzed using a fluorescent microscope system and the Image-Pro Plus software (v. 6.1) program (Media Cybernetics, Inc.).

Statistical analysis. All quantitative data are presented as mean values \pm S.D. as indicated. Statistical analysis of data was performed using the Student's $t$-test. Differences with a $P<0.05$ were considered significant.

\section{Conflict of Interest}

The authors declare no conflict of interest.

Acknowledgements. We thank Todd Schuster for technical assistance with flow cytometry, Alyssa Langfald for TUNEL assay and Nicki Brickman for assistance in submitting our manuscript. This work was supported by National Institutes of Health grants CA172457, CA166011, R37CA081064 and The Hormel Foundation.

1. Lin Y, Totsuka Y, He Y, Kikuchi S, Qiao Y, Ueda J et al. Epidemiology of esophageal cancer in Japan and China. J Epidemiol 2013; 23: 233-242.

2. Gaur P, Kim MP, Dunkin BJ. Esophageal cancer: recent advances in screening, targeted therapy, and management. J Carcinog 2014; 13: 11. 
3. Siegel R, Naishadham D, Jemal A. Cancer statistics for Hispanics/Latinos, 2012. CA Cancer J Clin 2012; 62: 283-298.

4. Wang J, Yi J. Cancer cell killing via ROS: to increase or decrease, that is the question Cancer Biol Ther 2008; 7: 1875-1884.

5. Sun X, Ai M, Wang Y, Shen S, Gu Y, Jin Y et al. Selective induction of tumor cell apoptosis by a novel P450-mediated reactive oxygen species (ROS) inducer methyl 3-(4-nitrophenyl) propiolate. J Biol Chem 2013; 288: 8826-8837.

6. Cerna D, Li H, Flaherty S, Takebe N, Coleman CN, Yoo SS. Inhibition of nicotinamide phosphoribosyltransferase (NAMPT) activity by small molecule GMX1778 regulates reactive oxygen species (ROS)-mediated cytotoxicity in a p53- and nicotinic acid phosphoribosyltransferase1 (NAPRT1)-dependent manner. J Biol Chem 2012; 287: 22408-22417.

7. Watson J. Oxidants, antioxidants and the current incurability of metastatic cancers. Open Biol 2013; 3: 120144

8. Mao L, Wertzler KJ, Maloney SC, Wang Z, Magnuson NS, Reeves R. HMGA1 levels influence mitochondrial function and mitochondrial DNA repair efficiency. Mol Cell Biol 2009; 29: $5426-5440$.

9. Trachootham D, Alexandre J, Huang P. Targeting cancer cells by ROS-mediated mechanisms: a radical therapeutic approach? Nat Rev Drug Discov 2009; 8: 579-591.

10. Rosen GM, Demos HA, Rauckman EJ. Not all aromatic nitro compounds form free radicals Toxicol Lett 1984; 22: 145-152.

11. Ding M, Shi X, Lu Y, Huang C, Leonard S, Roberts J et al. Induction of activator protein-1 through reactive oxygen species by crystalline silica in JB6 cells. J Biol Chem 2001; 276: 9108-9114.

12. Colavitti R, Pani G, Bedogni B, Anzevino R, Borrello S, Waltenberger J et al. Reactive oxygen species as downstream mediators of angiogenic signaling by vascular endothelial growth factor receptor-2/KDR. J Biol Chem 2002; 277: 3101-3108.

13. Irani K. Oxidant signaling in vascular cell growth, death, and survival: a review of the roles of reactive oxygen species in smooth muscle and endothelial cell mitogenic and apoptotic signaling. Circ Res 2000; 87: 179-183.

14. Liou GY, Storz P. Reactive oxygen species in cancer. Free Radic Res 2010; 44: 479-496.

15. Storz P. Reactive oxygen species in tumor progression. Front Biosci 2005; 10: 1881-1896.

16. Chamulitrat W, Spitzer JJ. Generation of nitro and superoxide radical anions from 2,4,6-trinitrobenzenesulfonic acid by rat gastrointestinal cells. Biochim Biophys Acta 1997; 1336: 73-82.

17. Ask K, Dijols S, Giroud C, Casse L, Frapart YM, Sari MA et al. Reduction of nilutamide by NO synthases: implications for the adverse effects of this nitroaromatic antiandrogen drug. Chem Res Toxicol 2003; 16: 1547-1554.

18. Cotter TG. Apoptosis and cancer: the genesis of a research field. Nat Rev Cancer 2009; 9 : 501-507.

19. D'Autreaux B, Toledano MB. ROS as signalling molecules: mechanisms that generate specificity in ROS homeostasis. Nat Rev Mol Cell Biol 2007; 8: 813-824.

20. Liu B, Chen Y St, Clair DK. ROS and p53: a versatile partnership. Free Radic Biol Med 2008; 44: 1529-1535.

21. Wu WS. The signaling mechanism of ROS in tumor progression. Cancer Metastasis Rev 2006; 25: 695-705.
22. Xu D, Rovira II, Finkel T. Oxidants painting the cysteine chapel: redox regulation of PTPs. Dev Cell 2002; 2: 251-252.

23. Langer DA, Das A, Semela D, Kang-Decker N, Hendrickson H, Bronk SF et al. Nitric oxide promotes caspase-independent hepatic stellate cell apoptosis through the generation of reactive oxygen species. Hepatology 2008; 47: 1983-1993.

24. Lee TJ, Kim EJ, Kim S, Jung EM, Park JW, Jeong SH et al. Caspase-dependent and caspase-independent apoptosis induced by evodiamine in human leukemic U937 cells. $\mathrm{Mol}$ Cancer Ther 2006; 5: 2398-2407.

25. Watabe M, Ito K, Masuda Y, Nakajo S, Nakaya K. Activation of AP-1 is required for bufalin-induced apoptosis in human leukemia U937 cells. Oncogene 1998; 16: 779-787.

26. Zhang Z, Wang CZ, Du GJ, Qi LW, Calway T, He TC et al. Genistein induces G2/M cell cycle arrest and apoptosis via ATM/p53-dependent pathway in human colon cancer cells. Int J Oncol 2013; 43: 289-296.

27. Shiloh Y, Ziv Y. The ATM protein kinase: regulating the cellular response to genotoxic stress, and more. Nat Rev Mol Cell Biol 2013; 14: 197-210.

28. Lin JJ, Dutta A. ATR pathway is the primary pathway for activating G2/M checkpoint induction after re-replication. J Biol Chem 2007; 282: 30357-30362.

29. Ray PD, Huang BW, Tsuji Y. Reactive oxygen species (ROS) homeostasis and redox regulation in cellular signaling. Cell Signal 2012; 24: 981-990.

30. Huang X, Tanaka T, Kurose A, Traganos F, Darzynkiewicz Z. Constitutive histone H2AX phosphorylation on Ser-139 in cells untreated by genotoxic agents is cell-cycle phase specific and attenuated by scavenging reactive oxygen species. Int $J$ Oncol 2006; 29: 495-501.

31. Zhu F, Zykova TA, Peng C, Zhang J, Cho YY, Zheng D et al. Phosphorylation of H2AX at Ser139 and a new phosphorylation site Ser16 by RSK2 decreases H2AX ubiquitination and inhibits cell transformation. Cancer Res 2011; 71: 393-403.

32. Siolas D, Hannon GJ. Patient-derived tumor xenografts: transforming clinical samples into mouse models. Cancer Res 2013; 73: 5315-5319.

33. Hidalgo M, Bruckheimer E, Rajeshkumar NV, Garrido-Laguna I, De Oliveira E, Rubio-Viqueira B et al. A pilot clinical study of treatment guided by personalized tumorgrafts in patients with advanced cancer. Mol Cancer Ther 2011; 10: 1311-1316.

(i) Cell Death and Disease is an open-access journal published by Nature Publishing Group. This work is licensed under a Creative Commons Attribution 4.0 International License. The images or other third party material in this article are included in the article's Creative Commons license, unless indicated otherwise in the credit line; if the material is not included under the Creative Commons license, users will need to obtain permission from the license holder to reproduce the material. To view a copy of this license, visit http://creativecommons.org/licenses/by/4.0/

Supplementary Information accompanies this paper on Cell Death and Disease website (http://www.nature.com/cddis) 